\title{
ESTUDO RETROSPECTIVO DOS CASOS DE DENGUE NO MUNICÍPIO DE SANTOS/SÃO PAULO ENTRE OS ANOS DE 2009 E 2013
}

\author{
RETROSPECTIVE STUDY OF CASES OF DENGUE IN SANTOS/SÃO PAULO \\ BETWEEN THE YEARS 2009 AND 2013
}

\author{
C. A. CRUZ ${ }^{2}$, E. M. N. PAULA ${ }^{1}$, C. S. L. NOGUEIRA ${ }^{2}$, R. B. MEIRELLES-BARTOLI ${ }^{1}$, \\ A. A. B. CARVALHO
}

\section{RESUMO}

A dengue é uma enfermidade considerada reemergente, causada pelo vírus do gênero Flavivírus e possui transmissão essencialmente urbana, Uma vez que a urbanização favoreceu o aumento do número de criadouros potenciais do Aedes aegypti, principal mosquito vetor. No Brasil a primeira epidemia da doença ocorreu no ano de 1982 com posterior declínio e um auge em 2002. Ainda é considerada um grave problema de saúde pública e seu controle é um grande desafio. Devido à isso, o presente trabalho teve como objetivo descrever a situação epidemiológica da dengue no município de Santos, estado de São Paulo, entre os anos de 2009 e 2013. Sendo assim, realizou-se um estudo retrospectivo descritivo, utilizando casos notificados provenientes do Centro de Vigilância Epidemiológica os quais foram avaliados de acordo com distribuição sazonal, meses e anos. O critério estatístico utilizado foi o Método dos Quartis. Observou-se que entre os anos de 2009 e 2013 foram notificados 18.918 casos de dengue no município de Santos, sendo que 51,87\% (9.812) desses casos ocorreram em 2013, 43,77\% ocorreram em 2010, (8.280). O primeiro semestre de todos os anos demonstrou maior representatividade quando comparado com o segundo, principalmente devido ao fato de ser o período de temperaturas mais elevada e altas taxas pluviométricas, favorecendo a reprodução do mosquito. Percebe-se que o número de notificações de casos da doença começa a aumentar em janeiro sendo que atinge um pico no mês de março e é decrescente nos meses seguintes, já que as chuvas diminuem, porém a doença sempre se apresenta em situação epidêmica. Além disso verificou-se que também em 2013 houve epidemia da doença. Sendo assim, nota-se que por meio de dados epidemiológicos e estatísticos, que a dengue ainda é uma enfermidade em situação epidêmica, representando um sério problema de saúde pública. Por isso, devem existir medidas de controle efetivas e que levem a um real diagnóstico de situação, para melhorar a situação epidêmica da dengue neste município..

PALAVRAS-CHAVE: EPIDEMIA, NOTIFICAÇÃO, REEMERGENTE, SAÚDE PÚBLICA.

ÁREA TEMÁTICA: Saúde Pública

\footnotetext{
${ }^{1}$ Universidade Federal de Goiás (UFG), Regional Jataí, Unidade Jatobá, Laboratório de Sanidade Animal

${ }^{2}$ Faculdade de Ciências Agrárias e Veterinárias da Universidade Estadual Paulista (UNESP) - Câmpus de Jaboticabal

*carol_a_cruz@yahoo.com.br
} 